\title{
CONDIÇÕES DE ACESSO À ATENÇÃO PRIMÁRIA À SAÚDE PELAS POPULAÇÕES RURAIS NO AGRESTE PERNAMBUCANO
}

\author{
CONDITIONS OF ACCESS TO PRIMARY HEALTH CARE BY \\ RURAL COMMUNITIES IN PERNAMBUCO'S AGRESTE REGION
}

\author{
José Roberto Henrique Souza Soares ${ }^{1}$ \\ Anselmo César Vasconcelos Bezerra ${ }^{2}$ \\ Alcindo José de $\mathrm{Sá}^{3}$
}

\section{RESUMO}

A Atenção Primária à Saúde é estratégica para as populações rurais. Portanto, buscou-se identificar as condições de acesso dos habitantes de áreas rurais aos serviços da atenção primária de Limoeiro e Cumaru, no Agreste de Pernambuco. Trata-se de uma pesquisa exploratória de natureza aplicada, na qual utilizaram-se técnicas qualitativas, como entrevistas semiestruturadas e análise de conteúdo na modalidade temática para sistematização dos resultados. Evidenciou-se que os municípios estão em fases diferentes de implementação da Estratégia Saúde da Família. Os principais problemas de acesso aos serviços públicos de saúde das populações rurais foram as distâncias geográficas, as condições das estradas e dos transportes, a ausência de estratégias formais da gestão municipal para esse público e a fragilidade na oferta de serviços básicos de saúde. Concluiu-se que Limoeiro apresentou maior capilaridade e protagonismo nas ações da atenção primária que Cumaru. Entretanto as ações ainda são incipientes para atender às demandas básicas das populações desses territórios.

Palavras-chaves: Acesso à saúde; População rural; Atenção primária à saúde; Promoção da saúde.

\begin{abstract}
The Atenção Primária à Saúde (APS - Primary Health Care) is strategic for rural populations. Therefore, In this paper, we identify the conditions of the rural population's access to primary care services in Limoeiro and Cumaru, which are cities in the Agreste region of Pernambuco. Qualitative techniques were used in this applied exploratory research, such as semi-structured interviews and thematic content analysis. It was evident that the municipalities are in different stages of the Estratégia Saúde da Família (ESF - Family Health Strategy) implementation. The main problems of access to public health services for rural populations were: the
\end{abstract}

\footnotetext{
1 Atualmente é Doutorando e Mestre em Geografia pela Universidade Federal de Pernambuco (UFPE). Licenciado em Geografia pelo Instituto Federal de Educação, Ciência e Tecnologia de Pernambuco (IFPE). email: roberto.henriquesoares@ufpe.br

2 Atualmente é Professor do Instituto Federal de Educação, Ciência e Tecnologia de Pernambuco (IFPE) nos cursos de Gestão Ambiental e Licenciatura em Geografia (Graduação) e Sustentabilidade Urbana e Educação Ambiental (Pós-graduação). Doutor e Mestre em Geografia pela Universidade Federal de Pernambuco (UFPE). e-mail: anselmo@recife.ifpe.edu.br

3 Atualmente é Professor Associado I do Departamento de Ciências Geográficas da Universidade Federal de Pernambuco-UFPE. Pós-Doutor em Filosofia do Direito pela Universidade de Sevilla-Espanha. Doutor em Geografia Humana pela Universidade de São Paulo. e-mail: alcindo@ufpe.br
} 
geographic distances; the conditions of roads and transportation; the lack of proper municipal management for this public and the limited provision of basic health services. It was concluded that Limoeiro presented greater capillarity and protagonism in primary care actions. However, efforts are still incipient to meet the basic demands of the population in these cities.

Keywords: Health accessibility; Rural population; Primary health care; Health promotion.

\section{INTRODUÇÃO}

As áreas rurais no Brasil muitas vezes são concebidas como espaços ligados ao atraso e ao frágil desenvolvimento socioeconômico, o que é uma percepção equivocada dada a dimensão continental do país e suas distintas realidades socioespaciais. Os povos rurais brasileiros podem ser caracterizados como Populações dos Campos, das Florestas e das Águas (PCFA) distinguindo-os entre si a partir das formas de reprodução social relacionadas predominantemente com o uso e a apropriação da terra (RUCKERT; CUNHA; MODENA, 2018).

Esses territórios são lugares representados pelos modos de vida campesino e transformados pelo crescente movimento do novo rural (WANDERLEY; FAVARETO, 2013). Diante dos fenômenos de pluriatividade e da intensificação de atividades não ligadas ao setor primário da economia, surgiu uma nova forma de compreensão dos espaços rurais, denominada de nova economia rural (VEIGA, 2004) que reverbera em diferentes contextos e condições de vida das populações desses espaços.

Neste contexto, um marco legal importante do setor saúde foi a implantação em 2011 da Política Nacional de Saúde Integral das Populações do Campo e da Floresta (PNSIPCF), que sofreu alterações em 2014, por meio da Portaria MS/GM no 2.311 para incluir o termo 'das Águas', passando a ser denominado de Política Nacional de Saúde das Populações do Campo, da Floresta e das Águas (PNSIPCFA) (BRASIL, 2013; 2014).

Tal política visa garantir e aprimorar as condições de acesso à saúde nas áreas rurais que possuem basicamente os serviços da Atenção Primária à Saúde (APS). Ao centrar as ações da APS no eixo funcional das doenças, muitos municípios transformaram as unidades em centros de pronto atendimento e lugares burocráticos de passagem para outros tipos de serviços (OLIVEIRA et al., 2015). É imperativo o desenvolvimento de estratégias que visem 
à adequação do novo modelo assistencial no desenvolvimento de ações próprias designadas pela APS nos contextos rurais (PITILIN; LENTSCK, 2015).

Essa pesquisa investigou as condições de acesso aos serviços da APS pelas populações rurais dos municípios pernambucanos de Limoeiro e Cumaru, considerando a distribuição espacial dos serviços de saúde nestes municípios, que negligenciam as dificuldades e características peculiares dos indivíduos residentes nos espaços rurais para organizar espacialmente os serviços ofertados. Portanto, realizou-se uma análise das condições de acesso aos serviços da APS, segundo relatos de usuários, profissionais da ESF nos territórios rurais e gestores de saúde dos dois municípios, tendo em vista as dificuldades de locomoção, comunicação e atendimento enfrentadas pelas populações do campo ao buscarem os serviços básicos de saúde.

\section{ACESSO À SAÚDE PELAS POPULAÇÕES RURAIS}

O Sistema Único de Saúde (SUS) enquanto estratégia de saúde pública ainda não tem atendido às especificidades das PCFA (SOARES et al., 2017). O acesso à saúde rural passa por um grande desafio que é a superação das distâncias para garantir atenção à saúde, o que coloca em cena outro componente, a atenção domiciliar (PESSOA; ALMEIDA; CARNEIRO, 2018). O acesso e acessibilidade aos serviços de saúde em espaços rurais ultrapassa a existência de uma Unidade de Saúde da Família (USF) nos territórios. Para se alcançar o acesso à saúde das populações rurais é necessário o fortalecimento da Estratégia Saúde da Família (ESF), por meio de visitas periódicas das equipes de saúde às residências, reduzindo assim as barreiras de acesso geográfico.

Na dimensão teórica da acessibilidade é possível identificar duas concepções distintas. Uma ligada aos aspectos socio-organizacionais, e outra que se refere ao enfoque geográfico, capaz de medir e analisar os impactos da distância e do tempo de locomoção, os custos necessários para o atendimento e o grau de influência que estes empecilhos podem provocar no acesso aos serviços de saúde por meio dos usuários (DONABEDIAN, 1980). A equidade vertical destaca-se como opção adequada aos sistemas de saúde, no sentido de promoverem a 
justiça social por meio de tratamentos desiguais, porém equilibrados, entre os usuários com condições e necessidades diferenciadas (SWARTZ, 2004). Assim, o acesso passa a se desenvolver sob uma concepção mais política do que operacional na APS (SANCHEZ; CICONELLI, 2012).

Ao analisar as dificuldades enfrentadas pela população indígena Xukuru do Ororubá, em Pesqueira no estado de Pernambuco, identificou-se que a situação geográfica das aldeias indígenas, a dispersão territorial e baixa densidade populacional constituem-se como empecilhos que dificultam o acesso desta população específica aos serviços de saúde (AZEVEDO; GURGEL; TAVARES, 2014). Faz-se necessário, portanto, a elaboração de estratégias que visem amenizar os obstáculos enfrentados por grupos tradicionais ocupantes de territórios com características rurais.

Tendo em vista a necessidade de uma cobertura universal e equânime da APS no Brasil, a população rural brasileira necessita ser considerada prioritariamente nas ações de promoção à saúde. O reconhecimento deste grupo como prioritário nas ações de controle, prevenção de agravos e promoção da saúde necessita ser pautado pelo reconhecimento do espaço rural como um território com dinâmica própria, organizado por meio de elementos culturais e econômicos capazes de interferir nas condições de saúde dos seus habitantes (PESSOA; ALMEIDA; CARNEIRO, 2018).

\section{MATERIAL E MÉTODOS}

Este estudo configura-se como uma pesquisa qualitativa de natureza aplicada com objetivo exploratório. Do ponto de vista procedimental constitui-se como um estudo de caso. Os procedimentos adotados basearam-se na revisão de literatura, nos trabalhos de campo e na realização de entrevistas semiestruturadas com usuários, profissionais da ESF nos territórios rurais e gestores de saúde dos municípios estudados. Foi utilizada a análise de conteúdo na modalidade temática para compreensão e discussão das informações coletadas (MINAYO, 2014). 


\section{Debates Insubmissos}

Revista

Os dois municípios estudados localizam-se na região de desenvolvimento do Agreste Setentrional de Pernambuco e apresentam padrões de ruralidade distintos (ARAGÃO, 2017). A escolha desses territórios foi realizada mediante a classificação de tipologia espacial dos municípios realizada pelo Instituto Brasileiro de Geografia e Estatística (IBGE, 2017), buscando verificar o impacto de diferentes ruralidades nas condições de acesso da população aos serviços prestados na APS.

Limoeiro destaca-se como um centro de zona capaz de articular as dinâmicas de circulação econômica da microrregião na qual se insere, possibilitando a integração entre a Região Metropolitana do Recife (RMR) e os municípios da parte norte do agreste pernambucano. Este município apresenta dimensão territorial de $273,739 \mathrm{~km}^{2}$, dividido entre áreas rurais e urbanas com predominância de setores censitários rurais (Figura 1). No entanto, a maior parte dos domicílios concentram-se na zona urbana, com 14.497 residências, enquanto na zona rural existem 1.721 domicílios espalhados por espaços que apresentam baixa densidade demográfica (IBGE, 2017; 2019).

Por sua vez, Cumaru é classificado na hierarquia urbana como um centro local. $\mathrm{Na}$ tipologia rural-urbana esse município é definido como rural adjacente, pois apresenta dependência dos serviços localizados nos centros de zona do entorno e possui distribuição dispersa da população pelo território. O território municipal possui extensão de $292,231 \mathrm{~km}^{2}$, e os setores censitários predominantes são os rurais (Figura 1), com 50\% das residências localizadas em espaços rurais e 50\% na área urbana, que somadas abrigam 10.906 habitantes (IBGE, 2017; 2019). 


\section{Revista
Debates Insubmissos}

Figura 1 - Localização de Limoeiro e Cumaru em Pernambuco, com destaque para os setores censitários dos municípios no ano de 2010

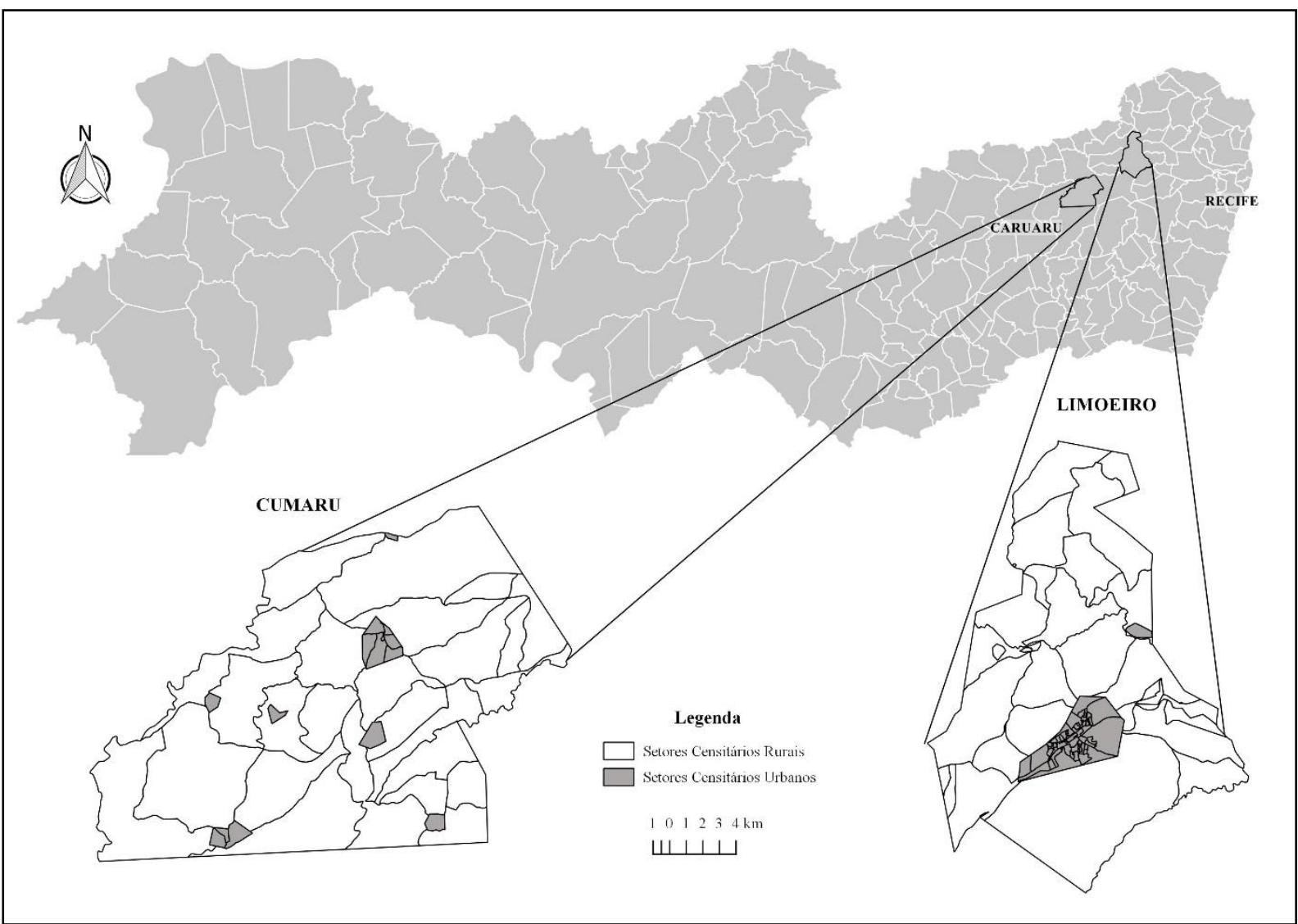

Para a identificação das condições de acesso aos serviços de saúde nas áreas rurais do município de Limoeiro recorreu-se a trabalhos de campo apoiados por alguns atores-chaves do território, especialmente das localidades dos Sítios Pitombeira, Guia, Várzea, Pinto e Vila Urucuba. Em Cumaru, participaram usuários, trabalhadores e gestores da APS do Sítio Cabaças, Gavião, Camarada, Vila Água Doce de Cima e Vila Poços. Essas localidades rurais situam-se em áreas distantes das sedes municipais e encontram-se em diferentes realidades socioespaciais nos municípios, pois são áreas que apresentam distribuição espacial das residências de maneira dispersa e estradas com condições de tráfego limitadas pela estrutura e tamanho, algumas delas impossibilitando a passagem de dois veículos de pequeno porte ao mesmo tempo. 
Para compreender a realidade vivenciada pela população rural desses municípios no que tange o acesso aos serviços da APS foram realizadas entrevistas semiestruturadas durante os anos de 2019 a 2020 com alguns atores selecionados (Quadro 1), que foram capazes de contribuir com informações sobre a conjuntura do acesso aos serviços de saúde pela população rural. O uso de elementos e informações empíricas obtidas por meio das narrativas e experiências dos entrevistados foram valorizados como elementos constitutivos dos resultados alcançados nesta pesquisa, tendo em vista que as aproximações teóricometodológicas do senso comum à ciência podem resultar na compreensão mais aproximada das condições de vida das populações (ALVES, 2015).

Quadro 1 - Quantidade de voluntários participantes das entrevistas nos municípios selecionados

\begin{tabular}{|c|c|c|c|}
\hline Municípios & Limoeiro & Cumaru & Total por Entrevistados \\
\hline Usuários (UAB) & 6 & 7 & 13 \\
\hline Profissionais (PAB) & 4 & 1 & 5 \\
\hline Gestores (GMS) & 1 & 2 & 4 \\
\hline Total por município & 12 & 10 & 21 \\
\hline
\end{tabular}

Fonte: Elaboração própria

Foram ouvidas 21 (vinte e uma) pessoas, de ambos os sexos, maiores de 18 anos e menor que 65 anos de idade, que por meio de suas experiências como usuários, profissionais e gestores dos serviços da ESF apresentaram os desafios das populações rurais no acesso aos serviços de saúde nos municípios de Cumaru e Limoeiro. Os instrumentos de entrevista foram estruturados de acordo com o tipo de participante da pesquisa, diferenciando-os por serem usuários, trabalhadores da APS ou membros da equipe de gestão em saúde. Nas entrevistas realizadas com os usuários destacaram-se perguntas acerca das dificuldades para acessarem os serviços de saúde e os mecanismos utilizados para superação dos obstáculos. Já os questionamentos realizados com os profissionais e a gestão de saúde desenvolveram-se com base em temas que abordaram o conhecimento sobre as dificuldades de acesso da população rural e o uso das estratégias especificadas na PNSIPCFA. 
A realização das entrevistas ocorreu por meio de contato prévio entre o pesquisador e os entrevistados, nos locais de trabalho, na residência dos usuários e nos estabelecimentos de saúde. Por meio de um diálogo inicial foram apresentadas as informações sobre a pesquisa, o objetivo e os principais assuntos que seriam tratados. Posteriormente, apresentou-se aos entrevistados o Termo de Consentimento Livre e Esclarecido (TCLE), que foi devidamente assinado pelos participantes.

As entrevistas foram gravadas em áudio, mediante consentimento dos participantes, com o uso de gravador de voz portátil, bem como foram realizadas entrevistas remotas nas quais os entrevistados foram orientados por ligação telefônica e enviaram as respostas via email. Posteriormente, as informações coletadas foram transcritas sem a identificação dos entrevistados.

Após essa etapa, passou-se à fase de análise de conteúdo, baseada na modalidade temática para a organização e estruturação das comunicações realizadas pelos voluntários. Essa análise buscou sistematizar os procedimentos adotados na verificação das comunicações, objetivando a inferência de conhecimentos acerca das informações prestadas (MINAYO, 2014). Esse material foi organizado em quadros, divididos pelos tipos de participantes (FERREIRA et al. 2020), identificados pela abreviatura informada no Quadro 1.

A pesquisa foi desenvolvida de acordo com os padrões éticos exigidos pela Resolução $n^{\circ}$ 466/2012 do Conselho Nacional de Saúde, tendo sido aprovada pelo Comitê de Ética em Pesquisa da Universidade Federal de Pernambuco sob parecer $n^{\circ}$ 4.517.687.

\section{RESULTADOS E DISCUSSÃO}

As condições do acesso apresentam consequências no uso e na disponibilidade aos serviços da ESF utilizadas pela população nos diferentes municípios. Os participantes desta pesquisa forneceram informações que refletem as características do tipo de espaço rural predominante nos municípios, desde os pequenos aglomerados populacionais aos domicílios 
dispersos pelo território, geralmente interligados por estradas vicinais, algumas vezes construídas exclusivamente para dar acesso às residências.

As dificuldades de locomoção e a necessidade de recursos financeiros para acessarem os transportes, e assim chegarem aos estabelecimentos de saúde, foram destacadas de forma mais frequente entre os usuários participantes desta pesquisa. Para o UAB 6, em algumas áreas rurais do município de Limoeiro as dificuldades intensificaram-se pelas condições das estradas, tornando-as áreas remotas. Já o UAB 5 considerou o agravamento das dificuldades para a população idosa das zonas rurais desta localidade, tendo em vista as limitações de locomoção provocadas por algumas doenças e a falta de assistência dos transportes da prefeitura. Entre as dimensões do acesso, a localização geográfica dos estabelecimentos de saúde é uma das principais condições que impacta na tomada de decisão da população para acessar os serviços de saúde (JENE; JAVIER; BERROCAL, 2017).

Para os UAB 2, 7, 8, 9, 10 e 11, a percepção em relação ao trabalho do Agente Comunitário de Saúde (ACS) é diversificada, com opiniões negativas em relação à baixa frequência de visitação ou mesmo a ausência deste profissional no território. Entretanto, o papel dos ACS nas áreas rurais dos municípios é primordial, uma vez que muitas famílias dependem unicamente desse serviço para acessarem os cuidados básicos de saúde (RUCKERT; CUNHA; MODENA, 2018). O UAB 2 afirmou que busca superar essa ausência pedindo apoio a outro ACS que não é responsável pelo território da sua residência, mas auxilia nas informações sobre os atendimentos e no fornecimento das medicações.

Quadro 2 - Análise Temática de Conteúdo dos Usuários da Atenção Primária em Saúde dos Municípios de Limoeiro-PE e Cumaru-PE em 2020

\begin{tabular}{|c|c|c|c|c|c|c|c|}
\hline \multirow[b]{3}{*}{$\begin{array}{l}\text { NÚCLEO } \\
\text { DE } \\
\text { SENTIDO }\end{array}$} & \multicolumn{6}{|c|}{ TEMAS } & \multirow[b]{3}{*}{$\begin{array}{c}\text { SÍNTESES } \\
\text { HORIZONTAIS }\end{array}$} \\
\hline & Doenças & \multicolumn{3}{|c|}{ Serviços de Saúde em Espaço Rural } & \multicolumn{2}{|c|}{$\begin{array}{c}\text { Condições de acesso aos serviços } \\
\text { de saúde em espaço rural }\end{array}$} & \\
\hline & $\begin{array}{l}\text { Presença } \\
\text { de doença } \\
\text { crônica }\end{array}$ & $\begin{array}{l}\text { Utilização dos } \\
\text { serviços de } \\
\text { saúde }\end{array}$ & $\begin{array}{c}\text { Serviços dos } \\
\text { agentes } \\
\text { comunitários } \\
\text { de saúde }\end{array}$ & $\begin{array}{c}\text { Serviços de } \\
\text { saúde no espaço } \\
\text { rural }\end{array}$ & $\begin{array}{l}\text { Dificuldades de } \\
\text { acesso }\end{array}$ & $\begin{array}{l}\text { Alternativas } \\
\text { para superar as } \\
\text { dificuldades de } \\
\text { acesso de } \\
\text { saúde }\end{array}$ & \\
\hline UAB 1 & $\begin{array}{l}\text { Não } \\
\text { possui }\end{array}$ & $\begin{array}{l}\text { Uso mensal da } \\
\text { APS }\end{array}$ & $\begin{array}{l}\text { Visitas } \\
\text { mensais na } \\
\text { residência }\end{array}$ & $\begin{array}{c}\text { Uma } \\
\text { ambulância para } \\
\text { emergências, } \\
\text { um posto de }\end{array}$ & $\begin{array}{l}\text { Custos com } \\
\text { transportes }\end{array}$ & $\begin{array}{l}\text { Medicina } \\
\text { Popular }\end{array}$ & $\begin{array}{l}\text { Os serviços da } \\
\text { ESF não } \\
\text { diminuem as } \\
\text { dificuldades de }\end{array}$ \\
\hline
\end{tabular}


Revista

Debates Insubmissos

\begin{tabular}{|c|c|c|c|c|c|c|c|}
\hline & & & & $\begin{array}{c}\text { saúde e a } \\
\text { Unidade de } \\
\text { Saúde da } \\
\text { Família (USF) }\end{array}$ & & & acesso \\
\hline UAB 2 & $\begin{array}{l}\text { Não } \\
\text { possui }\end{array}$ & $\begin{array}{c}\text { Uso mensal da } \\
\text { APS }\end{array}$ & $\begin{array}{c}\text { Visitas anuais } \\
\text { para atualizar } \\
\text { o cadastro }\end{array}$ & $\begin{array}{c}\text { Uma } \\
\text { ambulância para } \\
\text { emergências. }\end{array}$ & $\begin{array}{l}\text { Custos com } \\
\text { transportes }\end{array}$ & $\begin{array}{l}\text { Apoio de um } \\
\text { ACS de outra } \\
\text { área }\end{array}$ & $\begin{array}{c}\text { A ausência do } \\
\text { ACS provoca } \\
\text { dificuldades no } \\
\text { acesso a ESF } \\
\end{array}$ \\
\hline UAB 3 & $\begin{array}{l}\text { Não } \\
\text { possui }\end{array}$ & $\begin{array}{l}\text { Em casos de } \\
\text { emergência }\end{array}$ & $\begin{array}{l}\text { Visitas } \\
\text { mensais na } \\
\text { residência }\end{array}$ & $\begin{array}{l}\text { Posto de Saúde } \\
\text { que atende uma } \\
\text { vez por semana }\end{array}$ & $\begin{array}{l}\text { Locomoção e } \\
\text { superlotação } \\
\text { dos serviços }\end{array}$ & $\begin{array}{c}\text { Uso de } \\
\text { transportes } \\
\text { pagos }\end{array}$ & $\begin{array}{c}\text { A presença da } \\
\text { ESF não diminui } \\
\text { as dificuldades de } \\
\text { acesso }\end{array}$ \\
\hline UAB 4 & $\begin{array}{l}\text { Não } \\
\text { possui }\end{array}$ & $\begin{array}{l}\text { Uso semanal } \\
\text { da ESF para } \\
\text { controle de } \\
\text { doenças. }\end{array}$ & $\begin{array}{l}\text { Visitas } \\
\text { mensais na } \\
\text { residência. }\end{array}$ & $\begin{array}{l}\text { Existência da } \\
\text { USF na área } \\
\text { rural }\end{array}$ & $\begin{array}{l}\text { Ausência de } \\
\text { dificuldades }\end{array}$ & $\begin{array}{c}\text { Uso de } \\
\text { transportes } \\
\text { pagos }\end{array}$ & $\begin{array}{l}\text { Os pagamentos de } \\
\text { transportes } \\
\text { favorecem o } \\
\text { acesso }\end{array}$ \\
\hline UAB 5 & $\begin{array}{l}\text { Hiperten- } \\
\text { são }\end{array}$ & $\begin{array}{l}\text { Uso semanal } \\
\text { na USF e } \\
\text { periódico de } \\
\text { especialidades } \\
\text { no Recife }\end{array}$ & $\begin{array}{l}\text { Visitas } \\
\text { mensais na } \\
\text { residência }\end{array}$ & $\begin{array}{l}\text { Disponibilidade } \\
\text { de uma } \\
\text { ambulância para } \\
\text { emergências }\end{array}$ & $\begin{array}{l}\text { Locomoção da } \\
\text { população idosa } \\
\text { até a USF }\end{array}$ & $\begin{array}{c}\text { Uso de } \\
\text { transportes } \\
\text { pagos }\end{array}$ & $\begin{array}{l}\text { A população idosa } \\
\text { apresenta maiores } \\
\text { dificuldades de } \\
\text { locomoção }\end{array}$ \\
\hline UAB 6 & $\begin{array}{l}\text { Não } \\
\text { possui }\end{array}$ & $\begin{array}{c}\text { Uso mensal da } \\
\text { APS }\end{array}$ & $\begin{array}{l}\text { Visitas } \\
\text { mensais na } \\
\text { residência }\end{array}$ & $\begin{array}{c}\text { As } \\
\text { especialidades } \\
\text { são marcadas } \\
\text { pela SMS }\end{array}$ & $\begin{array}{l}\text { Problemas de } \\
\text { locomoção }\end{array}$ & $\begin{array}{c}\text { Uso de } \\
\text { transportes } \\
\text { pagos e } \\
\text { solicitação de } \\
\text { favores } \\
\end{array}$ & $\begin{array}{c}\text { O acesso aos } \\
\text { estabelecimentos } \\
\text { de saúde ocorre } \\
\text { mediante serviços } \\
\text { de terceiros }\end{array}$ \\
\hline UAB 7 & $\begin{array}{l}\text { Não } \\
\text { possui }\end{array}$ & $\begin{array}{l}\text { Uso em casos } \\
\text { de emergência }\end{array}$ & $\begin{array}{l}\text { Não existe } \\
\text { mais na zona } \\
\text { rural }\end{array}$ & $\begin{array}{l}\text { Não existem } \\
\text { serviços de } \\
\text { saúde no sítio }\end{array}$ & $\begin{array}{l}\text { Locomoção e a } \\
\text { falta do ACS }\end{array}$ & $\begin{array}{c}\text { Uso de } \\
\text { transportes } \\
\text { pagos, da água } \\
\text { de poços e } \\
\text { automedicação }\end{array}$ & $\begin{array}{l}\text { Pouca utilização } \\
\text { da ESF, mas } \\
\text { reconhece a } \\
\text { necessidade do } \\
\text { ACS na } \\
\text { comunidade rural }\end{array}$ \\
\hline UAB 8 & $\begin{array}{l}\text { Câncer de } \\
\text { pele }\end{array}$ & $\begin{array}{l}\text { Uso mensal de } \\
\text { serviços } \\
\text { complexos } \\
\text { fora do } \\
\text { município }\end{array}$ & $\begin{array}{l}\text { Não existe } \\
\text { mais no sítio }\end{array}$ & $\begin{array}{l}\text { Existência de } \\
\text { médicos na } \\
\text { UBS }\end{array}$ & $\begin{array}{l}\text { Diminuição das } \\
\text { dificuldades }\end{array}$ & $\begin{array}{l}\text { Automedicaçã } \\
\text { o e uso de } \\
\text { motos e carros } \\
\text { de familiares }\end{array}$ & $\begin{array}{c}\text { Apesar da } \\
\text { ausência do ACS } \\
\text { os serviços na } \\
\text { UBS estão } \\
\text { melhores }\end{array}$ \\
\hline UAB 9 & $\begin{array}{l}\text { Hiperten- } \\
\text { são }\end{array}$ & $\begin{array}{l}\text { Uso apenas } \\
\text { quando o } \\
\text { médico vai a } \\
\text { zona rural }\end{array}$ & $\begin{array}{l}\text { Não existe } \\
\text { mais no sítio }\end{array}$ & $\begin{array}{l}\text { Há uma } \\
\text { ambulância da } \\
\text { cidade para } \\
\text { emergências }\end{array}$ & $\begin{array}{l}\text { Locomoção e } \\
\text { falta do ACS }\end{array}$ & $\begin{array}{c}\text { Uso de } \\
\text { transportes } \\
\text { pagos } \\
\text { e recebimento } \\
\text { de medicações } \\
\text { por terceiros } \\
\end{array}$ & $\begin{array}{c}\text { Os serviços da } \\
\text { ESF são eventuais } \\
\text { com } \\
\text { características } \\
\text { precárias }\end{array}$ \\
\hline UAB 10 & $\begin{array}{l}\text { Não } \\
\text { possui }\end{array}$ & $\begin{array}{l}\text { Uso anual dos } \\
\text { serviços da } \\
\text { APS }\end{array}$ & Não é visitada & $\begin{array}{l}\text { Um PSF com } \\
\text { atendimentos } \\
\text { semanais }\end{array}$ & $\begin{array}{l}\text { Locomoção e } \\
\text { falta de } \\
\text { medicamentos }\end{array}$ & $\begin{array}{c}\text { Uso de } \\
\text { transportes } \\
\text { pagos } \\
\text { e de recursos } \\
\text { da medicina } \\
\text { popular }\end{array}$ & $\begin{array}{c}\text { Ausência de } \\
\text { serviços no Posto } \\
\text { de Saúde da } \\
\text { Família (PSF) } \\
\text { causa dificuldades } \\
\text { de locomoção }\end{array}$ \\
\hline UAB 11 & $\begin{array}{l}\text { Não } \\
\text { possui }\end{array}$ & $\begin{array}{l}\text { Uso anual dos } \\
\text { serviços da } \\
\text { APS }\end{array}$ & $\begin{array}{l}\text { Visitas } \\
\text { mensais na } \\
\text { residência }\end{array}$ & $\begin{array}{c}\text { Um prédio na } \\
\text { zona rural que já } \\
\text { foi um PSF, mas } \\
\text { não está em }\end{array}$ & $\begin{array}{l}\text { Dificuldades de } \\
\text { locomoção }\end{array}$ & $\begin{array}{l}\text { Procura de } \\
\text { serviços da } \\
\text { APS em } \\
\text { municípios }\end{array}$ & $\begin{array}{l}\text { A falta do ACS e } \\
\text { dos serviços da } \\
\text { APS, provoca } \\
\text { deslocamentos }\end{array}$ \\
\hline
\end{tabular}




\begin{tabular}{|c|c|c|c|c|c|c|c|}
\hline & & & & funcionamento & & $\begin{array}{l}\text { vizinhos e de } \\
\text { transportes } \\
\text { com } \\
\text { vereadores }\end{array}$ & $\begin{array}{l}\text { para outros } \\
\text { municípios }\end{array}$ \\
\hline UAB 12 & $\begin{array}{l}\text { Não } \\
\text { possui }\end{array}$ & $\begin{array}{c}\text { Uso mensal } \\
\text { dos serviços } \\
\text { da APS }\end{array}$ & $\begin{array}{l}\text { Visitas } \\
\text { mensais na } \\
\text { residência. }\end{array}$ & $\begin{array}{l}\text { O prédio de uma } \\
\text { UBS fechado }\end{array}$ & $\begin{array}{c}\text { Falta de } \\
\text { transportes e } \\
\text { ausência de } \\
\text { serviços básicos } \\
\text { no município }\end{array}$ & $\begin{array}{l}\text { Marcações dos } \\
\text { serviços } \\
\text { especializados } \\
\text { na SMS }\end{array}$ & $\begin{array}{c}\text { A ausência de } \\
\text { serviços da APS } \\
\text { na zona rural } \\
\text { dificulta o acesso } \\
\text { da população }\end{array}$ \\
\hline UAB 13 & $\begin{array}{l}\text { Hiperten- } \\
\text { são }\end{array}$ & $\begin{array}{c}\text { Uso mensal } \\
\text { dos serviços } \\
\text { da APS }\end{array}$ & $\begin{array}{l}\text { Visitas } \\
\text { mensais na } \\
\text { residência }\end{array}$ & $\begin{array}{l}\text { Um PSF com } \\
\text { atendimento } \\
\text { semanal e um } \\
\text { carro do } \\
\text { hospital da } \\
\text { cidade para } \\
\text { emergências }\end{array}$ & $\begin{array}{l}\text { Locomoção e a } \\
\text { alta demanda da } \\
\text { população }\end{array}$ & $\begin{array}{c}\text { Uso de } \\
\text { transportes } \\
\text { particulares, ou } \\
\text { pagos, a } \\
\text { medicina } \\
\text { popular e da } \\
\text { automedicação }\end{array}$ & $\begin{array}{l}\text { Apesar de utilizar } \\
\text { regularmente, os } \\
\text { serviços } \\
\text { apresentam falhas } \\
\text { de organização e } \\
\text { execução }\end{array}$ \\
\hline $\begin{array}{l}\text { Síntese } \\
\text { Vertical }\end{array}$ & $\begin{array}{l}\text { Boa parte } \\
\text { não possui } \\
\text { doenças } \\
\text { crônicas }\end{array}$ & $\begin{array}{c}\text { A maior parte } \\
\text { dos } \\
\text { voluntários } \\
\text { utilizam os } \\
\text { serviços de } \\
\text { saúde da APS }\end{array}$ & $\begin{array}{c}\text { Visitas } \\
\text { domiciliares } \\
\text { dos ACS em } \\
\text { quase todas as } \\
\text { famílias } \\
\text { entrevistadas }\end{array}$ & $\begin{array}{c}\text { Estratégias que } \\
\text { buscam a oferta } \\
\text { da ESF nos } \\
\text { espaços rurais }\end{array}$ & $\begin{array}{c}\text { Problemas de } \\
\text { distância aos } \\
\text { serviços e } \\
\text { transportes }\end{array}$ & $\begin{array}{c}\text { Utilizam } \\
\text { transportes } \\
\text { pagos, } \\
\text { automedicação } \\
\text { e medicina } \\
\text { popular }\end{array}$ & $\begin{array}{l}\text { A população rural } \\
\text { apresenta } \\
\text { dificuldades de } \\
\text { acesso provocadas } \\
\text { pelas condições } \\
\text { de locomoção e a } \\
\text { ausência de } \\
\text { serviços da ESF } \\
\text { na área rural }\end{array}$ \\
\hline & & & & & & & $\begin{array}{l}\text { SÍNTESE } \\
\text { GERAL }\end{array}$ \\
\hline
\end{tabular}

As populações dos municípios de Limoeiro e Cumaru enfrentam dificuldades que interferem nas condições de acesso aos serviços da ESF disponíveis nos espaços rurais desses territórios. Os principais desafios enfrentados pela população rural para alcançar os serviços da APS estão nas condições de locomoção e nas grandes distâncias que necessitam ser percorridas para os serviços de saúde (PESSOA; ALMEIDA; CARNEIRO, 2018).

Já no Município de Cumaru, a maioria dos usuários afirmaram não existir acompanhamento de um ACS em suas residências. Esse é um fator negativo, pois os ACS desenvolvem o trabalho de base essencial para a manutenção das condições saudáveis da população, em especial os residentes em espaços rurais, haja vista as dificuldades enfrentadas para se locomoverem até os estabelecimentos de saúde. A APS, assim como a Vigilância em Saúde apresentam importância singular para garantir o monitoramento das condições sanitárias dos territórios (BEZERRA; BITOUN, 2017). 


\title{
Revista \\ Debates Insubmissos
}

O GMS 3 destacou a ausência de serviços básicos nos espaços rurais como os relacionados ao saneamento ambiental, que é agravado pelo uso de água sem tratamento correto. O UAB 7 apresentou informações referentes à uma estratégia de superação dessa dificuldade no município de Cumaru, representada pela distribuição de produtos químicos que buscam amenizar os impactos do uso da água sem o tratamento adequado, conforme ilustra seu relato. No entanto, como existiam áreas sem acompanhamento de ACS, a população estava vulnerável às enfermidades pela falta de assistência domiciliar.

\begin{abstract}
Aqui não temos mais nenhum Agente de Saúde e isso é um problema, porque antes entregavam aqueles cloros pra colocar na água, sabemos que a água que a gente consome muitas vezes não é tratada, hoje, eu acho que só indo até o posto para conseguir o cloro, eles já não passam mais nas casas entregando. Isso é um problema, porque muitas vezes as pessoas também nem ligam de ir pegar no Posto de Água Doce de cima, que é o PSF mais próximo daqui (UAB 7).
\end{abstract}

Na superação dos problemas identificados pela população rural dos dois municípios evidenciou-se o pagamento pelos transportes informais, como as "lotações", que muitas vezes proporcionam riscos aos próprios usuários devido às condições de tráfego nas estradas e a superlotação dos veículos. Essa condição não é uma realidade apenas da população de municípios brasileiros: no Canadá, nos Estados Unidos e na Austrália, os habitantes de espaços rurais também fazem concessões de segurança para chegarem aos serviços de saúde (ARCURY et al. 2005; REGAN; WONG, 2009; MCGRAIL; HUMPHREYS, 2009). Somando-se a essa situação, a maioria afirmou realizar automedicação e uso das alternativas fitoterápicas, que são práticas comuns em áreas rurais, justificadas pelas dificuldades enfrentadas na busca pelos serviços da APS e por questões de ordem cultural (RUCKERT; CUNHA; MODENA, 2018).

Com relação à conjuntura dos serviços públicos de saúde ofertados à população rural do município de Limoeiro verificou-se a existência de ambulâncias localizadas nas áreas rurais para os casos de urgências. Também se constatou uma sistemática de marcações pela equipe da Secretaria Municipal de Saúde (SMS) para os serviços de média e alta complexidade, reduzindo o número de viagens dos usuários até a área urbana. Além disso, existe a oferta de um transporte para os tratamentos na capital do Estado, Recife. No entanto, ainda persistiam as dificuldades organizacionais das ações e estratégias adotadas pela SMS, 
como a falta de distribuição de medicamentos nas USF e pelos ACS, além da ausência de uma estratégia que busque amenizar os impactos provocados pelas distâncias que necessitam ser percorridas pela população rural das localidades mais remotas.

Os serviços de saúde disponíveis na zona rural desse município estavam organizados por meio da ESF e do NASF a partir das demandas de cada comunidade rural, contando com a estrutura de postos de apoio, que são estabelecimentos com menor dimensão e capacidade de oferta dos serviços, uma vez que serve como uma unidade de apoio da USF, atendendo a população duas vezes por semana.

No que tange à disponibilidade dos serviços públicos oferecidos à população rural do município de Cumaru, destacaram-se a existência de Unidades Básicas de Saúde (UBS) e Postos de Saúde da Família (PSF) que dispunham de atendimento médico semanalmente, enfermeiras e os demais profissionais da APS. Através dos tipos de estabelecimentos disponíveis nas áreas rurais estudadas percebe-se uma ação mais efetiva do município de Limoeiro em implantar a ESF nas áreas rurais, ao contrário de Cumaru, que mantém o modelo assistencial curativo e não apresenta as condições integrais para o cuidado e tratamento de saúde na área rural (PINTO; GIOVANELLA, 2018), mesmo sendo um município classificado como predominantemente rural (IBGE, 2017).

O UAB 8 destacou o serviço de transportes para emergências, mediante ligação telefônica para a unidade mista na sede urbana de Cumaru, que se desloca até a zona rural. $\mathrm{O}$ UAB 9 corroborou essa informação destacando a existência de um automóvel da SMS que deveria ficar na área rural para os atendimentos de emergência, porém esse transporte nunca ficou na UBS, e sempre que se faz necessário a população aguarda o socorro chegar da cidade para deslocar-se de volta até a sede do município e, assim, iniciar o atendimento das urgências.

De outra forma, foi relatado pelos UAB 11 e UAB 12 a existência de prédios, em zonas rurais de Cumaru, antes utilizados como estabelecimento de saúde e que até a data da coleta de dados desta pesquisa encontravam-se fechados. O GMS 3 confirmou a existência de postos de saúde que se encontravam em reforma, alguns inclusive com obras já concluídas, 
aguardando apenas a inauguração. No entanto, constatou-se a existência de 7 (sete) estabelecimentos de saúde localizados na zona rural do município desativados (CNES, 2019).

O problema do distanciamento geográfico é superado pelo uso de transportes alternativos, ou aluguel de veículos, que em ambos os casos requerem gastos financeiros por parte dos usuários. Também foi descrito, por uma das usuárias, práticas de apadrinhamento político para conseguir acessar os serviços públicos de saúde.

Não acontece comigo, mas outras pessoas daqui da comunidade procuram vereadores que vem com carro próprio pegar essas pessoas e levam ao serviço de saúde. Quando precisamos ser encaminhados do município pra outro lugar geralmente tem transporte da prefeitura, mas mediado por algum vereador, eles mandam o transporte até aqui e depois tem outro que leva até o Recife ou Caruaru, mas sempre tem um vereador de frente (UAB 11).

O UAB 11 destacou a existência de veículos da prefeitura municipal para realizar o transporte dos pacientes para outros municípios, no entanto, a marcação dos tratamentos e a disponibilidade desses serviços são alcançados pela população através de autoridades legislativas públicas que deveriam planejar, organizar e fiscalizar os serviços da prefeitura municipal e não usufruir de sua autoridade para barganhas políticas, através da prestação de favores para suprir as dificuldades enfrentadas pela população. O uso de trocas políticas para conseguir vantagens de acesso aos serviços públicos de saúde é uma estratégia que inviabiliza a distribuição dos equipamentos e tratamentos de saúde de maneira universal e igualitária, estas diretrizes estruturantes do SUS são negligenciadas quando práticas como as relatadas interferem no funcionamento adequado do fazer público em saúde (PESSOA; ALMEIDA; CARNEIRO, 2018).

Como os serviços da ESF não são realizados de maneira adequada, a população rural das áreas limítrofes busca acessar os serviços públicos de outras localidades vizinhas a Cumaru. Na porção oeste do município, onde localiza-se o Sítio Gavião, que faz fronteira com o território do município pernambucano de Riacho das Almas, o UAB 11 relatou que a população residente nesta área procura os serviços de saúde no município vizinho, devido à proximidade geográfica e à disponibilidade maior de equipamentos de saúde. 


\section{Revista \\ Debates Insubmissos}

Nos espaços rurais de Limoeiro os profissionais de saúde desenvolvem estratégias para amenizar as dificuldades enfrentadas pelos usuários visando garantir as condições de acesso da população aos serviços, fator que também é desenvolvido pelos trabalhadores de Cumaru (Quadro 3). Os profissionais que trabalham na APS desempenham um papel primordial para a garantia dos serviços de saúde à população. Estes são responsáveis pelo acolhimento no sistema e o tratamento das doenças, a partir das condições disponibilizadas pela equipe de gestão dos serviços (PITILIN; LENTSCK, 2015).

Quadro 3 - Análise Temática de Conteúdo dos Profissionais da Saúde em Espaços Rurais e da Gestão em Saúde dos municípios de Limoeiro-PE e Cumaru-PE em 2020

\begin{tabular}{|c|c|c|c|c|c|c|c|}
\hline \multirow[b]{3}{*}{$\begin{array}{c}\text { NÚCLEOS } \\
\text { DE } \\
\text { SENTIDO }\end{array}$} & \multicolumn{6}{|c|}{ TEMAS } & \multirow[b]{3}{*}{$\begin{array}{c}\text { SÍNTESE } \\
\text { HORIZONTAL }\end{array}$} \\
\hline & \multicolumn{2}{|c|}{ Local de Trabalho } & \multicolumn{4}{|c|}{ Acesso da População Rural aos Serviços de Saúde } & \\
\hline & Residência & $\begin{array}{c}\text { Área de } \\
\text { atendimento }\end{array}$ & $\begin{array}{l}\text { Atendimento em } \\
\text { serviços de saúde }\end{array}$ & $\begin{array}{c}\text { Dificuldades } \\
\text { de acesso }\end{array}$ & $\begin{array}{c}\text { Esforços } \\
\text { contra as } \\
\text { dificuldades }\end{array}$ & $\begin{array}{c}\text { Ações dos } \\
\text { governos para } \\
\text { amenizar as } \\
\text { dificuldades }\end{array}$ & \\
\hline PAB 1 & $\begin{array}{c}\text { Sítio } \\
\text { próximo }\end{array}$ & $\begin{array}{l}\text { A população da } \\
\text { área da USF, } \\
\text { bem como os } \\
\text { demais fora da } \\
\text { área }\end{array}$ & $\begin{array}{c}\text { Imunização; } \\
\text { consulta com } \\
\text { profissionais } \\
\text { variados, inclusive } \\
\text { especialistas }\end{array}$ & $\begin{array}{c}\text { Falta de } \\
\text { serviços } \\
\text { mais } \\
\text { complexos } \\
\text { no espaço } \\
\text { rural }\end{array}$ & $\begin{array}{c}\text { Atua } \\
\text { indicando os } \\
\text { serviços para } \\
\text { a população. }\end{array}$ & $\begin{array}{c}\text { Organização das } \\
\text { marcações sem } \\
\text { necessidade de } \\
\text { locomoção da } \\
\text { população para } \\
\text { a SMS }\end{array}$ & $\begin{array}{c}\text { Os serviços } \\
\text { prestados à } \\
\text { população não são } \\
\text { suficientes } \\
\text { quantitativamente }\end{array}$ \\
\hline PAB 2 & $\begin{array}{c}\text { Reside na } \\
\text { comunidade } \\
\text { rural em que } \\
\text { trabalha }\end{array}$ & $\begin{array}{l}\text { A população da } \\
\text { área da USF }\end{array}$ & $\begin{array}{c}\text { Visitas } \\
\text { domiciliares; } \\
\text { vacinação; } \\
\text { acompanhamento } \\
\text { de grupos de risco; } \\
\text { atendimento da } \\
\text { equipe da ESF e do } \\
\text { NASF }\end{array}$ & $\begin{array}{l}\text { Necessidade } \\
\text { de aumentar } \\
\text { a oferta de } \\
\text { serviços e } \\
\text { solucionar a } \\
\text { falta de } \\
\text { transportes. }\end{array}$ & $\begin{array}{c}\text { Os ACS } \\
\text { buscam os } \\
\text { ônibus das } \\
\text { escolas para } \\
\text { transportar } \\
\text { até a USF }\end{array}$ & $\begin{array}{l}\text { Existência de } \\
\text { uma ambulância } \\
\text { a disposição da } \\
\text { população rural }\end{array}$ & $\begin{array}{c}\text { As distâncias e a } \\
\text { falta de } \\
\text { profissionais } \\
\text { permanecem como } \\
\text { um empecilho no } \\
\text { acesso da população } \\
\text { rural }\end{array}$ \\
\hline PAB 3 & $\begin{array}{l}\text { Não reside } \\
\text { na } \\
\text { comunidade } \\
\text { rural }\end{array}$ & $\begin{array}{c}\text { Área urbana e } \\
\text { nas localidades } \\
\text { rurais }\end{array}$ & $\begin{array}{l}\text { Atendimento dos } \\
\text { profissionais da } \\
\text { ESF e do NASF. } \\
\text { Na USF e nos PSF }\end{array}$ & $\begin{array}{l}\text { Dificuldade } \\
\text { de } \\
\text { transportes, } \\
\text { necessitando } \\
\text { pagamentos }\end{array}$ & $\begin{array}{c}\text { Visitas } \\
\text { domiciliares } \\
\text { e a } \\
\text { divulgação } \\
\text { dos serviços } \\
\text { pelos ACS }\end{array}$ & $\begin{array}{l}\text { Ausência de } \\
\text { ações } \\
\text { relacionadas aos } \\
\text { problemas de } \\
\text { transportes }\end{array}$ & $\begin{array}{c}\text { Dificuldade de } \\
\text { locomoção para } \\
\text { chegar até o } \\
\text { estabelecimento de } \\
\text { saúde rural }\end{array}$ \\
\hline PAB 4 & $\begin{array}{l}\text { Reside na } \\
\text { área urbana }\end{array}$ & $\begin{array}{l}\text { A população da } \\
\text { área da USF }\end{array}$ & $\begin{array}{l}\text { Os profissionais da } \\
\text { ESF; } \\
\text { vacinações; } \\
\text { curativos; medição } \\
\text { de pressão; a } \\
\text { prevenção e } \\
\text { acompanhamento }\end{array}$ & $\begin{array}{c}\text { Dificuldades } \\
\text { de } \\
\text { locomoção }\end{array}$ & $\begin{array}{l}\text { Ampliação } \\
\text { do número } \\
\text { de } \\
\text { tratamentos } \\
\text { diários por } \\
\text { pacientes }\end{array}$ & $\begin{array}{c}\text { Oferta de um } \\
\text { ônibus para os } \\
\text { pacientes que } \\
\text { precisam ir até o } \\
\text { Recife }\end{array}$ & $\begin{array}{c}\text { Apesar da } \\
\text { dificuldade de } \\
\text { locomoção da } \\
\text { população rural, o } \\
\text { município oferece } \\
\text { transporte para os } \\
\text { serviços de alta } \\
\text { complexidade }\end{array}$ \\
\hline PAB 5 & $\begin{array}{l}\text { Reside na } \\
\text { área urbana }\end{array}$ & $\begin{array}{c}\text { Áreas próximas } \\
\text { da UBS }\end{array}$ & $\begin{array}{c}\text { Visitas } \\
\text { domiciliares, } \\
\text { atendimento } \\
\text { médico, } \\
\text { psiquiátrico e }\end{array}$ & $\begin{array}{c}\text { Pagamento } \\
\text { de } \\
\text { transportes } \\
\text { para a UBS } \\
\text { ou Unidade }\end{array}$ & $\begin{array}{l}\text { Orientação } \\
\text { aos pacientes } \\
\text { sobre os } \\
\text { serviços da } \\
\text { UBS }\end{array}$ & $\begin{array}{l}\text { Disponibiliza } \\
\text { médicos e } \\
\text { enfermeiras na } \\
\text { zona rural }\end{array}$ & $\begin{array}{l}\text { A UBS atende áreas } \\
\text { rurais além da } \\
\text { urbana em que está } \\
\text { localizada e a } \\
\text { população necessita }\end{array}$ \\
\hline
\end{tabular}




\begin{tabular}{|c|c|c|c|c|c|c|c|}
\hline & & & $\begin{array}{l}\text { distribuiçãa de } \\
\text { remédios }\end{array}$ & Mista & & & pagar transportes \\
\hline GMS1 & $*$ & $*$ & $\begin{array}{c}\text { A ESF como } \\
\text { estratégia } \\
\text { específica voltada } \\
\text { para a população } \\
\text { rural } \\
\end{array}$ & $*$ & $*$ & $\begin{array}{c}\text { As UBS } \\
\text { atendem um dia } \\
\text { a mais na } \\
\text { semana, no } \\
\text { sábado }\end{array}$ & $\begin{array}{l}\text { A ESF garante os } \\
\text { serviços à } \\
\text { população rural }\end{array}$ \\
\hline GMS 2 & $*$ & $\begin{array}{l}\text { Existência de } 6 \\
\text { UBS que } \\
\text { atendem a } \\
\text { população } \\
\text { urbana e rural } \\
\text { do município }\end{array}$ & $\begin{array}{l}\text { Equipes da ABS, } \\
\text { do PACS e do } \\
\text { NASF, além dos } \\
\text { atendimentos } \\
\text { domiciliares e dos } \\
\text { transportes }\end{array}$ & $\begin{array}{c}\text { Falta de } \\
\text { ações } \\
\text { voltadas para } \\
\text { a população } \\
\text { rural }\end{array}$ & $\begin{array}{c}\text { O problema } \\
\text { de resistência } \\
\text { ao modelo } \\
\text { preventivo de } \\
\text { saúde, } \\
\text { ocasionado } \\
\text { pela falta de } \\
\text { educação e } \\
\text { informação }\end{array}$ & $\begin{array}{c}\text { Disponibilidade } \\
\text { de transportes } \\
\text { nas áreas rurais, } \\
\text { e para Recife ou } \\
\text { Caruaru, além } \\
\text { da abertura de } \\
\text { novos PSF }\end{array}$ & $\begin{array}{l}\text { Necessidade de } \\
\text { ações voltadas para } \\
\text { o contexto da } \\
\text { população rural }\end{array}$ \\
\hline GMS 3 & $*$ & $\begin{array}{l}4 \text { UBS e } 3 \text { PSF, } \\
\text { além de mais } 3 \\
\text { para serem } \\
\text { reabertos }\end{array}$ & $\begin{array}{l}\text { As equipes da ABS } \\
\text { e nas áreas } \\
\text { descobertas atuam } \\
\text { o PACS, e o projeto } \\
\text { Saúde Itinerante, } \\
\text { com as equipes da } \\
\text { ABS e do NASF } \\
\text { mensalmente }\end{array}$ & $\begin{array}{c}\text { Há } \\
\text { necessidade } \\
\text { de mais UBS } \\
\text { e PSF } \\
\text { distribuídos } \\
\text { pela zona } \\
\text { rural }\end{array}$ & $\begin{array}{c}\text { As distâncias } \\
\text { que são } \\
\text { percorridas } \\
\text { para chegar } \\
\text { as UBS e/ou } \\
\text { PSF e a falta } \\
\text { de } \\
\text { saneamento } \\
\text { ambiental }\end{array}$ & $\begin{array}{l}\text { A estratégia de } \\
\text { promoção da } \\
\text { saúde, através } \\
\text { de orientações } \\
\text { pelos ACS e a } \\
\text { distribuição de } \\
\text { suplementos } \\
\text { para tratamento } \\
\text { de água e dos } \\
\text { serviços da } \\
\text { ABS }\end{array}$ & $\begin{array}{c}\text { Dificuldade de } \\
\text { locomoção da } \\
\text { população, que é } \\
\text { suprimida pelas } \\
\text { visitas domiciliares } \\
\text { dos profissionais da } \\
\text { ESF }\end{array}$ \\
\hline $\begin{array}{l}\text { Síntese } \\
\text { Vertical }\end{array}$ & $\begin{array}{l}\text { A maioria } \\
\text { dos } \\
\text { profissionais } \\
\text { não residem } \\
\text { no espaço } \\
\text { rural em que } \\
\text { trabalham. }\end{array}$ & $\begin{array}{l}\text { A área atendida } \\
\text { é maior do que a } \\
\text { estipulada } \\
\text { territorialmente } \\
\text { para as USF }\end{array}$ & $\begin{array}{l}\text { As áreas rurais } \\
\text { dispõem dos } \\
\text { serviços da ESF e } \\
\text { do NASF }\end{array}$ & $\begin{array}{c}\text { A } \\
\text { dificuldade } \\
\text { de } \\
\text { locomoção } \\
\text { destaca-se } \\
\text { entre as } \\
\text { demais } \\
\text { limitações }\end{array}$ & $\begin{array}{l}\text { Utilizam } \\
\text { recursos } \\
\text { variados e } \\
\text { criativos para } \\
\text { superar os } \\
\text { desafios }\end{array}$ & $\begin{array}{l}\text { A SMS busca } \\
\text { amenizar as } \\
\text { dificuldades da } \\
\text { população na } \\
\text { maioria das } \\
\text { vezes }\end{array}$ & $\begin{array}{l}\text { As condições dos } \\
\text { transportes e das } \\
\text { estradas são } \\
\text { empecilhos no } \\
\text { acesso à saúde pela } \\
\text { população rural }\end{array}$ \\
\hline
\end{tabular}

* Informação não consultada, pois a estrutura das entrevistas alterou-se de acordo com a função dos participantes ou o participante absteve-se da resposta.

Fonte: Elaboração Própria

Os profissionais e a gestão dos serviços públicos de saúde no município de Limoeiro apresentaram conhecimento acerca das dificuldades específicas enfrentadas pelas populações rurais. Muitos profissionais da USF Virgílio Lapenda destacaram o uso de alternativas criativas para auxiliar a população na diminuição dos impactos causados pelo distanciamento locacional entre os estabelecimentos de saúde e as residências, bem como a ausência de serviços em alguns territórios. O NASF é utilizado na prestação continuada dos serviços de saúde no município, sendo responsável por suprir a falta de algumas especialidades básicas na USF. 


\section{Revista \\ Debates Insubmissos}

Somos do NASF, que é o Núcleo de Apoio a Saúde da Família, uma vez por mês ou de quinze em quinze dias dependendo da demanda da população, os profissionais como farmacêutico, assistente social, nutricionista, psicólogo, fisioterapeuta e o educador físico vem para unidade (PAB 3).

A PAB 3 identificou que os diversos profissionais buscam implementar as práticas desenvolvidas na USF e auxiliar os usuários com atendimentos nas residências e nas unidades de saúde amenizando os impactos do distanciamento locacional comum nos territórios rurais. Por meio de atendimentos mais próximos e com especialistas que buscam diminuir os agravos de saúde na população, as equipes do NASF da SMS de Limoeiro buscam desenvolver suas atividades.

As PAB 2 e 4 identificaram a necessidade de recursos financeiros para arcar com os custos de transporte como uma dificuldade marcante para que os indivíduos cheguem aos serviços de saúde da APS. A PAB 2 destacou que muitas vezes os ACS da zona rural de Limoeiro buscam apoio dos motoristas de ônibus escolares, para que os usuários com maiores dificuldades financeiras e de locomoção possam acessar os serviços oferecidos nos estabelecimentos rurais. Percebe-se, assim, uma tática de adaptação à ausência de transportes públicos desenvolvida pelos trabalhadores da ESF do município de Limoeiro.

As questões de deslocamento dos profissionais de saúde pelo território também é um fator importante na concepção do acesso. A disponibilidade de transportes para as equipes da ESF realizarem o trabalho nos territórios rurais torna-se uma dificuldade que interfere na qualidade do acesso da população. Para a PAB 2 existem problemas de atraso ou até mesmo a falta de veículos para que os profissionais possam chegar até à população na zona rural de Limoeiro.

A GMS 1 destacou a necessidade de uma estratégia de saúde específica voltada para a população rural. Mesmo dispondo da ESF e do NASF no município de Limoeiro, as condições específicas dos habitantes das zonas rurais necessitam ser enfrentadas com medidas que busquem amenizar os impactos do distanciamento geográfico e da falta de recursos econômicos. As PCFA sofrem demasiadamente devido à falta de estratégias locais elaboradas 
pelas gestões municipais e estaduais para que garantam os serviços da ESF às populações rurais respeitando suas condições socioeconômicas e culturais (OLIVEIRA et al., 2015).

Os profissionais de saúde do município de Cumaru que atuavam nos espaços rurais realizam suas atividades dentro dos limites territoriais estabelecidos pelas microrregiões que formam as USF, sediadas por uma UBS e os Postos de Saúde. A PAB 5 afirmou trabalhar em comunidades rurais próximas da UBS, mas residia na área urbana do município. Dentre as atividades destacadas pela profissional são relatadas as visitas domiciliares pelos ACS e a equipe de médicos e enfermeiros que realizam visitas periódicas aos pacientes com doenças crônicas, além do atendimento na UBS da comunidade Água Doce de Cima, onde localiza-se a sede de uma das USF. Neste estabelecimento são realizadas consultas semanais e o desenvolvimento de atividades de prevenção e promoção da saúde, voltadas para os aspectos curativos das doenças (PINTO; GIOVANELLA, 2018).

Corroborando as informações prestadas pelos usuários participantes deste estudo, a PAB 5 destacou como principal empecilho para a população rural chegar aos serviços de saúde, a necessidade de pagamentos para utilização de transportes que levam a população para a UBS ou a Unidade Mista na sede urbana da localidade. As condições socioeconômicas dos indivíduos destacaram-se como um dos fatores preponderantes na definição dos determinantes sociais da saúde. Ao utilizar a determinação social como modelo de compreensão crítica dos sistemas de saúde percebe-se que o acesso da população depende de fatores referentes aos indivíduos e à sociedade organizada por meio do Estado, que deve garantir as condições essenciais de acesso e cuidado à saúde (BREILH, 2013).

Para o GMS 2 e o GMS 3, o aspecto cultural também interfere nas condições de acesso dos residentes em espaços rurais provocando o distanciamento das práticas de prevenção de doenças e promoção da saúde. Assim, persiste o modelo de busca dos serviços de saúde para os tratamentos curativos e não para a prevenção e promoção.

Além das dificuldades de locomoção, destacam-se a resistência que persiste na população baseada no modelo curativo de saúde, então a implantação das estratégias de prevenção e promoção sofrem empecilhos. Estas práticas são consequências da falta de informação e educação com relação aos serviços prestados no município (GMS 2). 
A resistência dessa parcela da população em buscar os serviços de saúde para os tratamentos menos complexos resulta na necessidade da oferta de serviços de média e alta complexidade que não são ofertados no município, provocando assim deslocamentos maiores para localidades que oferecem esses serviços. As transformações ocorridas nos espaços rurais brasileiros, provocadas pela exacerbação do modelo capitalista de produção, proporcionaram um estilo de vida predador da população rural, impulsionando práticas que negligenciam os cuidados essenciais à vida dos indivíduos, como o uso de agrotóxicos ou os modelos de trabalho por arrendamento de terras e assalariamento, nos quais a população utiliza o espaço de terceiros mediante pagamento pelo uso das terras, impedindo que as pessoas busquem os serviços em situações menos graves por priorizarem o trabalho no campo (RIGOTTO et al. 2012)

A ausência de acompanhamento domiciliar realizado pelos ACS nas áreas rurais de Cumaru intensifica as dificuldades enfrentadas pelos usuários na busca pelos serviços públicos de saúde. Tal situação representa uma contradição entre os usuários e a gestão municipal de saúde que afirmou possuir $100 \%$ (cem por cento) de cobertura do território municipal por meio das ações da APS e do NASF. As condições de educação da população rural interferem no acesso destes aos serviços de saúde, o baixo nível de alfabetização dos indivíduos habitantes dos espaços rurais é considerado um obstáculo no acesso aos serviços de saúde disponíveis (ASSIS; JESUS, 2012). Na busca de superação dessa problemática o trabalho dos ACS torna-se essencial devido à possibilidade de divulgação das informações de saúde e articulação entre os usuários e os serviços (BEZERRA; BITOUN, 2017).

O GMS 3 destacou uma estratégia desenvolvida para superar a falta de assistência da APS em algumas áreas rurais do município, que foi denominada de Saúde Itinerante. Esta ação foi desenvolvida em áreas descobertas do território, proporcionando a visita mensal de toda a equipe da ESF e do NASF. O gestor ainda afirmou que a equipe do Programa Agentes Comunitários de Saúde (PACS) é responsável por atender as áreas descobertas, porém como são espaços dispersos, o trabalho do ACS torna-se inviável. É perceptível o esforço da SMS de Cumaru na realização de atividades que busquem amenizar os impactos do distanciamento 
locacional dos residentes em espaços rurais mediante ações pontuais, que não soluciona definitivamente os problemas, mas proporcionam atenção periódica.

Verificou-se que os municípios estão em fases diferentes de implementação da Estratégia Saúde da Família (ESF) no âmbito da APS. Em Limoeiro existem estratégias de atenção à saúde baseadas na legislação que estabelece as diretrizes para a concretização de uma assistência integral por meio da ESF (PINTO; GIOVANELLA, 2018). Enquanto em Cumaru, a estratégia de assistência em saúde permanece baseada no modelo anterior a implantação da ESF. O fato de ser um município com características mais rurais não justifica esse atraso na implementação de um modelo que apresenta resultados importantes em vários outros municípios do estado e do país (PITILIN; LENTSCK, 2015).

\section{CONSIDERAÇÕES FINAIS}

Os principais problemas de acesso aos serviços públicos de saúde das populações rurais de Limoeiro e Cumaru, no agreste pernambucano, caracterizam-se pelas distâncias geográficas, pelas condições das estradas e dos transportes, pela ausência de estratégias formais da gestão municipal para esse público e a fragilidade na oferta de serviços básicos no âmbito da ESF. De maneira analítica, conclui-se que o município de Limoeiro apresentou maior capilaridade e protagonismo nas ações da APS se comparado com as ações e atividades desenvolvidas pelo município de Cumaru. Entretanto, as estratégias de saúde voltadas para a população rural em ambos os municípios ainda são incipientes, impossibilitando o atendimento as demandas básicas das populações rurais destes territórios.

As diretrizes da PNSIPCFA não são consideradas efetivamente no planejamento e desenvolvimento das ações nos municípios estudados. Portanto, faz-se necessária a divulgação e fiscalização por parte dos diferentes atores sociais, conforme as condições estabelecidas na PNSIPCFA, bem como o interesse por parte dos administradores públicos em aplicar a política em seus territórios. Numa perspectiva de justiça social, o princípio da equidade do SUS deve ser objetivado a partir do enfrentamento das dificuldades e demandas variadas em consequência da heterogeneidade das realidades vivenciadas pelas populações. 
Os habitantes dos espaços rurais dos municípios de Limoeiro e Cumaru apresentam dificuldades de acesso representadas pela disposição geográfica dos estabelecimentos de saúde no território municipal, pela falta de cobertura adequada da APS, pela frágil política de mobilidade e custeio dos transportes, pela falta de medicamentos e ainda por percorrerem longas distâncias para acessar os serviços da ESF, concentrados em USF e demais estabelecimentos. Esses empecilhos devem ser considerados na elaboração das políticas municipais e estaduais de saúde para garantir condições básicas na entrada do sistema de atendimento de saúde.

A busca pela integração entre os diversos atores responsáveis pelo SUS nos municípios, estados e na federação é um fator primordial para que as políticas públicas de saúde sejam desenvolvidas plenamente nos territórios. Dessa maneira, as ações da APS em áreas rurais poderão ser guiadas no sentido da universalidade e da equidade necessárias para que o acesso aos serviços básicos seja garantido de maneira eficaz. Assim, as populações rurais necessitam ser inseridas nas políticas públicas de saúde por meio das especificidades determinadas pelo tipo de espaço em que residem e trabalham com o objetivo de assegurar as condições de saúde estabelecidas na PNSIPCFA.

Algumas limitações devem ser consideradas na realização desta pesquisa, como a participação de apenas uma profissional de saúde em Cumaru, decorrente do receio e não consentimento de participação nas entrevistas de profissionais de saúde do município, bem como a participação de apenas uma integrante da Secretaria Municipal de Saúde (SMS) de Limoeiro, restringindo os dados a um número variado entre os municípios e atores participantes.

Diante do exposto, considera-se os recursos metodológicos utilizados nesta pesquisa como instrumentos capazes de serem utilizados pela gestão de serviços públicos de saúde para compreender a realidade vivida pelos usuários residentes em territórios rurais. Ou ainda, servir como base para que outros estudos de caráter mais específico sejam desenvolvidos nas mais diversas escalas e realidades que compõem as ruralidades brasileiras. 


\section{REFERÊNCIAS}

ALVES, Rubem. Filosofia da ciência: introdução ao jogo e a suas regras. 19 ed. São Paulo: edições Loyola, 2015.

ASSIS, Marluce Maria Araújo; JESUS, Washington Luiz Abreu de. Acesso aos serviços de saúde: abordagens, conceitos, políticas e modelo de análise. Ciência \& Saúde Coletiva, v. 17, n. 6, p. 2865-2875, 2012.

ARAGÃO, João Paulo Gomes de Vasconcelos. Uso e ocupação das margens do rio Capibaribe: vulnerabilidades socioambientais em áreas urbanas. 2017. Tese (Doutorado em Desenvolvimento e Meio Ambiente) - Centro de Filosofia e Ciência Humanas da Universidade Federal de Pernambuco, Recife, 2017. 294p.

ARCURY, Thomas A.; GESLER, Wilbert M.; PREISSER, John S.; SHERMAN, Jill; SPENCER, John; PERIN, Jaime. The effects of geography and spatial behavior on health care utilization among the residents of a rural region. Health Services Research. v. 40, n.1, p. 135-156, 2005.

AZEVEDO, Ana Lucia Martins de; GURGEL, Idê Gomes Dantas; TAVARES, Maurício Antunes. O poder de acessar a saúde: uma análise do acesso à saúde na etnia indígena Xukuru do Ororubá, Pesqueira (PE). Cadernos de Saúde Coletiva. v. 22, n. 3, p. 275-280, 2014.

BEZERRA, Anselmo César Vasconcelos; BITOUN, Jan. Metodologia participativa como instrumento para a territorialização das ações da Vigilância em Saúde Ambiental. Ciência \& Saúde Coletiva, v. 22, n. 10, p. 3259-3268, 2017. DOI: 10.1590/1413812320172210.17722017

BRASIL, Ministério da Saúde. Portaria $n^{\circ}$ 2.866/2011. Política nacional de saúde integral das populações do campo e da floresta. Brasília: MS, 2013. Disponível em: http://bvsms.saude.gov.br/bvs/publicacoes/politica_nacional_saude_populacoes_campo.pdf. BRASIL. Ministério da Saúde. Portaria n ${ }^{\circ}$ 2.311, de 23 de outubro de 2014. Altera a Política nacional de saúde integral das populações do campo e da floresta. Brasília: MS, 2014. Disponível em: http://bvsms.saude.gov.br/bvs/saudelegis/gm/2014/prt2311_23_10_2014.html

BREILH, Jaime. La determinación social de la salud como herramienta de transformación hacia uma nueva salud pública (salud colectiva). Rev. Fac. Nac. de Salud Pública, v. 31, n.1, p. 13-27, 2013.

CNES, Cadastro Nacional de Estabelecimentos de Saúde. Ministério da Saúde. Pesquisa de Estabelecimentos de Saúde [acessado 2019 Jul 12] Disponível em: http://cnes.datasus.gov.br/pages/estabelecimentos/consulta.jsp 
DONABEDIAN, Avedis. Methods for deriving criteria for assessing the quality of medical care. Medical Care Review, v. 37, n. 7, p. 653, 1980.

FERREIRA, Andressa Martins Dias et al. Roteiro adaptado de análise de conteúdo modalidade temática: relato de experiência. Journal of Nursing and Health, v. 10, n. 1. p. 1$10,2020$.

GENE, Francisco Javier Hernández; BERROCAL, Rosana Garnica. Accesibilidad física de la población a servicios de salud pública en San Pelayo y Cereté, Córdoba, Colombia, año 2015. Perspectiva Geográfica, v. 22, n. 2, p. 67-84, 2017.

IBGE, Instituto Brasileiro de Geografia e Estatística. Classificação e caracterização dos espaços rurais e urbanos do Brasil: uma primeira aproximação. Rio de Janeiro: IBGE/Coordenação de Geografia, 2017.

IBGE, Instituto Brasileiro de Geografia e Estatística. Estimativas populacionais dos municípios em 2019: Instituto Brasileiro de Geografia e Estatística. Rio de Janeiro: IBGE, 2019. Disponível em: https://sidra.ibge.gov.br/tabela/6579.

MCGRAIL, Matthew R.; HUMPHREYS, John S.. A new index of access to primary care services in rural areas. Australian and New Zealand Journal of Public Health, v. 33, n. 5, p. 418-423, 2009.

MINAYO, Maria Cecília de Souza. O desafio do conhecimento: pesquisa qualitativa em saúde. São Paulo: Hucitec Editora, 2014.

OLIVEIRA, Edward Meirelles de et al. Determinantes sócio-históricos do cuidado na Estratégia Saúde da Família: a perspectiva de usuários da área rural. Saúde e Sociedade, v. 24, n. 1, p. 901-913, 2015.

PESSOA, Vanira Matos; ALMEIDA, Magda Moura; CARNEIRO, Fernando Ferreira. Como garantir o direito à saúde para as populações do campo, da floresta e das águas no Brasil? Saúde em Debate, v. 42, n.1, p. 302-314, 2018.

PINTO, Luiz Felipe; GIOVANELLA, Ligia. Programa à Estratégia Saúde da Família: expansão do acesso e redução das internações por condições sensíveis à atenção básica (ICSAB). Ciência \& Saúde Coletiva, v. 23, n. 6, p. 1903-1914, 2018. Disponível em: https://doi.org/10.1590/1413-81232018236.05592018

PITILIN, Érica de Brito; LENTSCK, Maicon Henrique. Atenção Primária à Saúde na percepção de mulheres residentes na zona rural. Revista da Escola de Enfermagem da USP, v. 49, n. 5, p. 726-732, 2015. Available from: https://doi.org/10.1590/S0080623420150000500003 .

REGAN, Sandra; WONG, Sabrina T. Patient perspectives on primary health care in rural 
communities: effects of geography on access, continuity and efficiency. Rural and Remote Health, v. 9, p. 1-12, 2009.

RIGOTTO, Raquel Maria et al. O verde da economia no campo: desafios à pesquisa e às políticas públicas para a promoção da saúde no avanço da modernização agrícola. Ciência \& Saúde Coletiva, v. 17, n. 6, p. 1533-1542, 2012.

RÜCKERT, Bianca; CUNHA, Daisy Moreira; MODENA, Celina Maria. Saberes e práticas de cuidado em saúde da população do campo: revisão integrativa da literatura. Interface Comunicação, Saúde, Educação. Botucatu-SP, v. 22, n. 66, p. 1-12, 2018. Available from: DOI: $10.1590 / 1807-57622017.0449$.

SANCHEZ, Raquel Maia; CICONELLI, Rozana Mesquita. Conceitos de acesso à saúde. Revista Panamericana de Salud Pública, v. 31, p. 260-268, 2012.

SWARTZ, Omar. On Social Justice and Political Struggle, Essay. Human Nature Review, v. 4, n.12. 2004. pp. 56-63.

SOARES, Rackynelly Alves Sarmento et al. A invisibilidade da população do campo, da floresta e das águas no Brasil: desafio para os sistemas de informações em saúde. In:

CARNEIRO, F.F.; PESSOA, V.M.; TEIXEIRA, A.C.A. (Org.) Campo, Florestas e Águas: Práticas e saberes em saúde. Brasília: Editora Universidade de Brasília. 2017. pp. 56-58.

VEIGA, José Eli da. A dimensão rural do Brasil. Estudos Sociedade e Agricultura. v. 12, n. 1, p. 71-94. 2004.

WANDERLEY, Maria de N.B.; FAVARETO, Arilson. A singularidade do rural brasileiro: implicações para as tipologias territoriais e a elaboração de políticas públicas. In: MIRANDA C. (org.) Concepções da ruralidade contemporânea: as singularidades brasileiras. Brasília: IICA, p. 413-473, 2013.

Submetido: $10 / 06 / 2021$

Aprovado: 26/08/2021 